\title{
Valtion katastrofiapu ja satovahinkovakuutusten kysyntä Suomessa
}

\author{
Petri Liesivaara $^{1}$, Sami Myyrä ${ }^{1}$ ja Minna Väre ${ }^{1}$ \\ ${ }^{1}$ MTT Taloustutkimus, Latokartanonkari 9,00790 Helsinki, etunimi.sukunimi@mtt.fi
}

\section{TIIVISTELMÄ}

Epävakaat sääolosuhteet vaikuttavat satovahinkovakuutusten markkinoihin merkittävästi. Satoriskien systeemisyyden takia valtion osallistuminen myös satovahinkojen vakuuttamiseen on usein välttämätöntä. Valtioiden yleisesti käytössä olevia keinoja ovat vakuutusmaksujen tuki, satoriskien jälleenvakuuttaminen ja valtion antama katastrofiapu. Satovakuutuksiin yleisesti liittyvien moraalikadon ja haitallisen valikoitumisen lisäksi satovahinkovakuutusmarkkinoiden syntymiseen vaikuttaa myös valtion viljelijöille antama katastrofiapu.

Suomessa satovahinkoja korvataan valtion kokonaan rahoittaman satovahinkokorvausjärjestelmän kautta. Järjestelmä loppuu vuonna 2015. Samaan aikaan uudistettavassa EU:n yhteisessä maatalouspolitiikassa annetaan maatalouden riskienhallinnalle entistä suurempi painoarvo. Tulevaisuudessa satovahinkoja korvattaisiin valtion ja yksityisten vakuutusyhtiöiden yhdessä tarjoamilla satovahinkovakuutuksilla. EU:ssa ehdolla on tuki satovahinkovakuutusten vakuutusmaksuille. Tuki vakuutusmaksuihin voisi olla enintään 75 $\%$ vakuutuksen hinnasta. Tuettujen satovakuutusten omavastuun tulee olla vähintään $30 \%$.

Tuettujen satovahinkovakuutusten markkinat ovat omavastuun ja valtion antaman katastrofiavun välissä. Vaarana on, että valtion katastrofiapu viljelijöille vähentää satovakuutusten kysyntää niin paljon, että markkinoiden syntymiselle ei ole edellytyksiä. Tässä tutkimuksessa selvitettiin satovahinkovakuutusten kysyntää ja maksuhalukkuutta Suomessa sekä tarkasteltiin valtion katastrofiavun vaikutusta satovahinkovakuutusten kysyntään ja maksuhalukkuuteen.

Tutkimuksessa käytettiin valintakoemenetelmää. Valintakoemenetelmä perustuu oletukseen, että viljelijöiden kokema kokonaishyöty satovahinkovakuutuksista voidaan jakaa osiin vakuutuksen attribuuttien suhteen. Valintakokeeseen valitut vakuutusten attribuutit olivat: Hinta, omavastuu, vakuutuksen tyyppi ja odotettavissa oleva vakuutuskorvaus. Katastrofiavun vaikutusta viljelijöiden maksuhalukkuuteen tutkittiin jaetulla aineistolla.

Vastaajien iällä oli negatiivinen vaikutus satovakuutustuotteiden kysyntään. Lisäksi tilan sijainti Pohjois- tai Itä-Suomessa vaikutti negatiivisesti satovakuutusten kysyntään. Sen sijaan tilan viljelyala lisäsi vakuutustuotteiden kysyntää. Kysyntä oli myös suurempaa kasvinviljelytiloilla ja silloin, kun viljelijä oli saanut aikaisempina vuosina korvauksia satovahinkokorvausjärjestelmästä.

Valtion katastrofiavun mahdollisuudella ei ollut vaikutusta valittujen vakuutustuotteiden määrään. Sen sijaan valtion katastrofiavulla oli merkittävä vaikutus viljelijöiden maksuhalukkuuteen. Viljelijöiden maksuhalukkuus satovahinkotuotteista oli matalampi silloin, kun valtio edelleen myönsi katastrofiapua, mutta sen ehdoksi oli asetettu vapaaehtoisen satovahinkovakuutuksen hankkiminen. Jos valtio haluaa tukea markkinoiden kehittymistä satovahinkovakuutuksille, katastrofiavun mahdollisuus lisää tuen tarvetta ja näin ollen lisää veronmaksajien rahan käyttöä.

Asiasanat: katastrofiapu, satovakuutus, valintakoemenetelmä, maksuhalukkuus 


\section{Johdanto}

Satovahingot ovat luonteeltaan systeemisiä, jonka takia valtion osallistuminen satovahinkojen vakuuttamiseen on usein välttämätöntä (Miranda ja Glauber 1997). Valtioiden yleisesti käytössä olevia keinoja ovat vakuutusmaksujen tuki, satoriskien jälleenvakuuttaminen ja valtion antama katastrofiapu. Satovakuutuksiin yleisesti liitetään moraalikadon ja haitallisen valikoitumisen eli epäsymmetrisen informaatioon liittyvät ongelmat (Hardaker ym. 2004). Näiden tekijöiden lisäksi satovahinkovakuutusmarkkinoiden syntymiseen vaikuttaa valtion viljelijöille antama katastrofiapu. Kun laajamittainen luonnonolosuhteista johtuva katastrofi toteutuu, yhteiskunnassa on sosiaalinen ja poliittinen paine auttaa viljelijöitä. Valtion myöntämällä katastrofiavulla on kuitenkin merkittävä vaikutus yksityisten vakuutusyhtiöiden tarjoamien satovakuutusten kysyntään.

Suomessa satovahinkoja on korvattu valtion kokonaan rahoittaman satovahinkokorvausjärjestelmän kautta. Järjestelmä päättyy vuonna 2015. Samaan aikaan Euroopan yhteistä maatalouspolitiikkaa uudistetaan. Ehdolla satovahinkojen korvaamiseen on tuki vakuutusmaksuihin osana maaseudun kehittämistä. Tuki voi olla enintään $75 \%$ satovahinkovakuutuksen hinnasta. Tuettujen vakuutusten omavastuu tulee olla vähintään $30 \%$ (EC 2013).

Satovakuutusten markkinat ovat omavastuun ja valtion myöntämän katastrofiavun välissä. Tuettujen vakuutusten rajaksi määritetty $30 \%$ omavastuun raja saattaa olla liian korkea, jos valtio samaan aikaan tarjoaa katastrofiapua mittavien satoriskien sattuessa. Tässä tutkimuksessa selvitettiin satovahinkovakuutusten kysyntää ja maksuhalukkuutta Suomessa sekä tarkasteltiin valtion katastrofiavun vaikutusta satovahinkovakuutusten kysyntään ja maksuhalukkuuteen. Tutkimuksessa käytettiin valintakoemenetelmää.

\section{Aineisto ja menetelmä}

Valintakokeessa käytettävä aineisto kerättiin 5000 suomalaiselle viljelijälle suunnatulla kyselyllä. Lähetetyistä kyselylomakkeista 1170 palautui. Osana kyselyä viljelijöille esitettiin kuusi satovakuutustuoteparia, joista vastaajaa pyydettiin valitsemaan itselleen sopivin. Vastaajalla oli myös mahdollisuus olla ostamatta satovakuutusta (Kuvio 1). Kun puuttuvat vastaukset poistettiin aineistosta, valintakoetta varten kerätty aineisto sisälsi 6105 havaintoa.

\begin{tabular}{|c|c|c|c|}
\hline Vakuutuskortti 1 & Vakuutus 1 & Vakuutus 2 & $\begin{array}{c}\text { En ostaisi kumpaakaan } \\
\text { vakuutusta }\end{array}$ \\
\hline Vakuutuksen hinta $€ /$ ha & 12 & 16 & \\
\hline Omavastuu & $20 \%$ & $20 \%$ & \\
\hline Vakuutuksen tyyppi & $\begin{array}{c}\text { Satoindeksivakuutus -ei } \\
\text { edellytä vahinkotarkastusta } \\
\text { tilalla } \\
\end{array}$ & $\begin{array}{c}\text { Tilan satovakuutus - } \\
\text { edellyttää vahinkotarkastuk- } \\
\text { sen tilalla } \\
\end{array}$ & \\
\hline Vakuutuskorvaus $€ /$ ha & 300 & 600 & \\
\hline VALINTANI & $\square$ & $\square$ & $\square$ \\
\hline
\end{tabular}

Kuvio 1. Esimerkki valintakortista.

Vakuutustuotteiden ominaisuuksiksi valintakokeeseen valittiin vakuutuksen hinta (euroa/ha), omavastuu, vakuutuksen tyyppi ja odotettavissa oleva vakuutuskorvaus (euroa/ha). Vakuutustuotteiden ominaisuuksien tasot on esitetty taulukossa 1 . Vakuutustyypeiksi tutkimukseen valittiin indeksivakuutus ja tilakohtainen vakuutus. Indeksivakuutuksessa korvaukset perustuvat ennalta määritettyyn tilastoon tai indeksiin. Tilakohtaisessa vakuutuksessa korvaukset perustuvat tilalla havaittuun satoon. Vakuutustuotteiden ominaisuudet selvitettiin kyselylomakkeella huolellisesti vastaajille ennen valintakortteja.

Taulukko 1. Vakuutustuotteiden ominaisuuksien tasot.

\begin{tabular}{lr}
\hline Ominaisuus & Tasot \\
\hline Hinta & $4,8,12,16,24,32 € / \mathrm{ha}$ \\
Omavastuu & $10,20,30 \%$ \\
Vakuutuskorvaus & $100,300,600 € / \mathrm{ha}$ \\
Vakuutustyyppi & Indeksivakuutus, Tilakohtainen vakuutus \\
\hline
\end{tabular}


Ennen vakuutuskortteja vastaajille annettiin kaksi toisistaan poikkeavaa alkuasetelmaa. Puolessa kysymyslomakkeista esitettiin, että valtio ei enää missään olosuhteissa osallistu satovahinkojen korvaamiseen. Puolessa lomakkeista ilmoitettiin, että valtio voi osallistua satovahinkojen korvaamiseen sillä edellytyksellä, että viljelijä on hankkinut vapaaehtoisen satovahinkovakuutuksen (Taulukko 2).

Taulukko 2. Vastaajille annetut alkuasetelmat ennen valintakortteja.

\section{Vastaajajoukko EI.}

Muistakaa, että yhteiskunta ei missään tapauksessa enää osallistu satovahinkojen korvaamiseen.

\section{Vastaajajoukko KYLLÄ.}

Muistakaa, että yhteiskunta saattaa joissain satovahinkotapauksissa jakaa ns. katastrofiapua. Katastrofiavun edellytyksenä kuitenkin on, että teillä on oma vapaaehtoinen satovahinkovakuutus.

Viljelijöiden maksuhalukkuuden selvittämiseen käytettiin ekonometrisia menetelmiä (McFadden 2001). Valintakoemenetelmä perustuu oletukseen siitä, että hyödykkeen antama kokonaishyöty voidaan jakaa hyödykkeen ominaisuuksien (attribuuttien) tasolle. Siinä toisaalta oletetaan, että kuluttaja pystyy erottamaan attribuutit toisistaan ja että vastaaja pystyy laittamaan attribuuttien antamat hyödyt omalta kannaltaan tärkeysjärjestykseen. Menetelmässä vastaaja valitsee esitetyistä hyödykekoreista sen, joka tuottaa hänelle suurimman hyödyn. Valintakoemenetelmässä hyödykkeen kokonaishyöty U voidaan siis jakaa tuotteen attribuutteihin $\mathrm{Z}$ ja sosioekonomisiin taustamuuttujiin $\mathrm{S}$ :

$U_{\text {in }}=V_{\text {in }}\left(Z_{i}, S_{n}\right)+\varepsilon_{\text {in }}$

Missä,

$\mathrm{U}_{\text {in }}=$ vaihtoehdon $\mathrm{i}$ antama hyöty henkilölle $\mathrm{n}$

$\mathrm{V}_{\text {in }}=$ selitettävissä oleva osa hyödystä

$\mathrm{Z}_{\mathrm{i}}=$ attribuutit

$\mathrm{S}_{\mathrm{n}}=$ sosioekonomiset taustamuuttujat

$\varepsilon_{\text {in }}=$ satunnaisvaihtelu

Mallinnuksessa luovuttiin virhetermien $\varepsilon_{\text {in }}$ yhtäsuuruusoletuksesta käyttämällä mixed logit mallin sovellusta error component logit mallia $(\mathrm{ECM})$, jossa estimoitavaan hyötyfunktioon lisätään ylimääräinen virhetermi. Käytännössä tämä tarkoittaa sitä, että mallinnuksessa otettiin mahdollisimman hyvin huomioon viljelijöiden erilaiset mieltymykset ja riskiasenteet. Mixed logit mallin estimoitava todennäköisyys eri valinnoille on (Train 2003):

$d \beta$,

missä $f(\beta)$ on tiheysfunktio, jonka kuvaamasta jakaumasta saadaan painot mixed logit mallin ennustamille todennäköisyyksille. Mixed logit malli antaa siis painotetun keskiarvon logit mallin tuloksille painotettuna eri $\beta: n$ arvoilla. Mixed logit mallissa estimoidut parametriestimaatit voivat vaihdella vastaajittain, kuvastaen erilaisia mieltymyksiä ja riskiasenteita.

Koska logit mallin avulla estimoidaan vastaajan saamaa hyötyä hyödykkeestä, parametrien estimaateilla ei ole taloudellista tulkintaa. Koska hinta on yksi mallin estimoitavista attribuuteista, parametrien arvoista on kuitenkin mahdollista laskea vastaajien marginaaliset maksuhalukkuudet eri vakuutustuotteiden ominaisuuksille. Marginaalinen maksuhalukkuus kertoo kuinka paljon vastaaja olisi valmis maksamaan yhden yksikön suuruisesta muutoksesta kyseiseen attribuuttiin. Marginaaliset maksuhalukkuudet (Implicit Prices, IP) on laskettu seuraavasti:<smiles>CCCC</smiles>

missä $\beta_{\mathrm{k}}$ on $k$ attribuutin parametriestimaatti, ja $\beta_{\mathrm{p}}$ on hinta attribuutin parametriestimaatti. 


\section{Tulokset}

ECM malliin lisättiin sosioekonomisia muuttujia satovakuutuksia todennäköisimmin ostavien viljelijöiden selvittämiseksi. Aikaisempien satovakuutuksien kysyntää selvittävien tutkimuksista poiketen (Sherrick ym. 2004; Mishra ja Goodwin 2003) iällä oli negatiivinen vaikutus satovakuutusten kysyntään. Tulokset olivat kuitenkin samansuuntaisia Velandian ym. (2009) tulosten kanssa. Satovakuutukset ovat monimutkaisia ja täysin uusia tuotteita viljelijöille. Nuoret viljelijät saattavat olla halukkaampia ottaa käyttöön uusia riskienhallinnan työkaluja. Nuoret viljelijät saattavat myös nähdä satovakuutukset ajankohtaiseksi tuotteeksi itselleen erityisesti tulevaisuudessa.

Satovakuutusten kysyntä lisääntyi tilan viljeltävien hehtaarien funktiona. Sen sijaan kysyntä oli pienempää Pohjois- ja Itä-Suomessa. Satovakuutusten kysyntä oli odotetusti suurempaa myös kasvinviljelytiloilla. Lisäksi satovakuutusten kysyntä oli suurempaa, mikäli tila oli saanut korvauksia satovahinkojärjestelmästä viimeisten 18 vuoden aikana.

Katastrofiavun vaikutusta satovakuutusten kysyntään tutkittiin jaetulla aineistolla. Toisessa aineistossa valtio ei missään satovahinkotapauksissa myönnä katastrofiapua. Toisessa aineistossa katastrofiapu on mahdollista, mutta sen ehdoksi on asetettu vapaaehtoinen satovahinkovakuutus. Molemmista aineistoista estimoitiin parametrien arvot erikseen error component logit mallille. Parametrien arvoista laskettiin implisiittiset hinnat vakuutustuotteiden attribuuteille käyttäen Krinskyn ja Robbin (1986) ehdottamaa menetelmää. Implisiittisten hintojen eroa kahdessa eri aineistossa testattiin t-testillä. Implisiittiset hinnat, niiden ero ja t-arvot on esitetty Taulukossa 3.

Taulukko 3. Implisiittisten hintojen mediaani, muutos (\%) ja t-arvot kahdessa eri aineistossa.

\begin{tabular}{|l|c|c|c|c|}
\hline & $\begin{array}{c}\text { Katastrofiapu ei } \\
\text { mahdollinen } \\
\text { (EI) }\end{array}$ & $\begin{array}{c}\text { Katastrofiapu } \\
\text { mahdollinen } \\
\text { (KYLLÄ) }\end{array}$ & $\begin{array}{c}\text { Keskimääräinen } \\
\text { \% muutos } \\
\text { ((EI-KYLLÄ)/-EI) }\end{array}$ & t-arvo \\
\hline Omavastuu & $-31,67$ & $-38,94$ & $-23,0 \%$ & 64,91 \\
Odotettavissa oleva vakuutuskorvaus & 0,038 & 0,041 & $8,4 \%$ & 21,50 \\
Tilavakuuutus & $-19,76$ & $-27,66$ & $-39,9 \%$ & 41,13 \\
Indeksivakuutus & $-17,31$ & $-25,00$ & $-44,5 \%$ & 39,73 \\
\hline
\end{tabular}

Suuret t-arvot osoittavat, että ero maksuhalukkuuksissa kahden politiikan välillä on merkittävä. Viljelijöiden maksuhalukkuus omavastuusta oli 23 \% suurempi EI aineistossa. Sen sijaan maksuhalukkuus vakuutuksen kattavuudesta eli odotettavissa olevista vakuutuskorvauksista oli 8,4 \% matalampi EI aineistossa. Viljelijöiden maksuhalukkuus molemmissa vakuutustyypeistä oli korkeampi EI aineistossa. Implisiittisistä hinnoista voidaan luoda vakuutustuotteita, jotka osoittavat maksuhalukkuuden erilaisista vakuutustuotteista vaihtelevilla vakuutustuotteiden ominaisuuksilla. Taulukossa 4 on kuvattu viljelijöiden maksuhalukkuus tilakohtaisesta satovakuutuksesta $30 \%$ omavastuulla kolmella eri odotettavissa olevan vakuutuskorvauksen tasolla.

Taulukko 4. Viljelijöiden maksuhalukkuus $30 \%$ omavastuun tilakohtaisesta satovakuutuksesta kahdessa eri aineistossa ja maksuhalukkuuksien erotus.

\begin{tabular}{|c|c|c|c|c|c|c|c|c|c|}
\hline & \multicolumn{3}{|c|}{$\begin{array}{c}\text { Katastrofiapu ei mahdol- } \\
\text { linen(EI) }\end{array}$} & \multicolumn{3}{|c|}{$\begin{array}{c}\text { Katastrofiapu } \\
\text { mahdollinen (KYLLÄ) }\end{array}$} & \multicolumn{4}{|c|}{} \\
\cline { 2 - 10 } & $\begin{array}{c}\text { Odotettavissa oleva va- } \\
\text { kuutuskorvaus } € \text { /ha }\end{array}$ & \multicolumn{2}{|c|}{$\begin{array}{c}\text { Odotettavissa oleva } \\
\text { vakuutuskorvaus } € \text { /ha }\end{array}$} & \multicolumn{3}{c|}{ Erotus $€$ (\%) } \\
\cline { 2 - 10 } Omavastuu & $\mathbf{1 0 0}$ & $\mathbf{3 0 0}$ & $\mathbf{5 0 0}$ & $\mathbf{1 0 0}$ & $\mathbf{3 0 0}$ & $\mathbf{5 0 0}$ & $\mathbf{1 0 0}$ & $\mathbf{3 0 0}$ & $\mathbf{5 0 0}$ \\
\hline $\mathbf{3 0} \%$ & 6,2 & 13,7 & 21,2 & 3,7 & 11,8 & 19,9 & $-2,5(-40,5 \%)$ & $-1,9(-13,7 \%)$ & $-1,2(-5,9 \%)$ \\
\hline
\end{tabular}

Kun vakuutuksen omavastuu on $30 \%$ ja odotettavissa oleva vakuutuskorvaus on $100 € /$ ha, viljelijöiden maksuhalukkuus tilakohtaisesta satovakuutuksesta on 40,5\% pienempi KYLLÄ aineistossa EI aineistoon verrattuna. Samalla omavastuun tasolla, mutta odotettavissa olevan vakuutuskorvauksen ollessa 500 $€ /$ ha, viljelijöiden maksuhalukkuus on vain 5,9 \% pienempi KYLLÄ aineistossa. Katastrofiavun mahdolli- 
suus vaikuttaa siis eniten niiden satovakuutusten maksuhalukkuuteen, joissa on pieni odotettavissa oleva vakuutuskorvaus. Tähän kategoriaan kuuluvat viljakasvien satovakuutukset, jotka kattavat noin puolet Suomen viljelyalasta.

\section{Johtopäätökset}

Tutkimuksen tuloksilla on merkittävä vaikutus satovakuutusten kehittämiseen ja valtion politiikan suunnitteluun koskien katastrofiapuun satovahinkotapauksissa. EU:ssa tuettujen satovakuutusten omavastuun raja on asetettu $30 \%$ :iin. Jos vakuutustuotteet suunnitellaan antamaan pieni kattavuus satovahinkojen varalta, valtion katastrofiavulla on suuri negatiivinen vaikutus viljelijöiden maksuhalukkuuteen. Tämä johtaa siihen, että valtion on käytettävä korkeita vakuutusmaksutukia satovakuutuksille, jos se haluaa mahdollisimman monen viljelijän ostavan vakuutuksen. Tämä johtaa veronmaksajien rahojen ylimääräiseen käyttämiseen.

\section{Kirjallisuus}

EC 2013. Proposal for a Regulation of the European Parliament and of the Council on Support for Rural Development by the European Agricultural Fund for Rural Development (EAFRD). Working document $\begin{array}{llll}\text { European } & \text { Council. } & \text { Brussels. } & \text { 6.9.2013 }\end{array}$ http://register.consilium.europa.eu/pdf/en/13/st13/st13349.en13.pdf

Hardaker, J. B., Huirne, R. B. M., Andersson, J. R. \& Lien, G. 2004. Coping with risk in agriculture. CABI Publishing. London.

Krinsky, I. \& Robb, A. 1986. On approximating the statistical properties of elasticities. The Review of Economics and Statistics 68(4): 715-719

McFadden, D. 2001. Economic choices. The American Economic Review 91(3): 351-378

Miranda, M. J. \& Glauber, J. W. 1997. Systemic risk, reinsurance, and the failure of crop insurance markets. American Journal of Agricultural Economics 79(1): 206-215

Mishra, A. K. \& Goodwin, B. K. 2003. Adoption of crop insurance versus revenue insurance: A farm level analysis. Agricultural Finance Review 63(22): 144-155

Sherrick, B. J., Barry, P. J., Ellinger, P. N. \& Schnitkey, G. D. 2004. Factors Influencing Farmers' Crop Insurance Decisions. American Journal of Agricultural Economics 86(1): 103-114

Train, K. 2003. Discrete choice methods with simulation. Cambridge University Press.

Velandia, M., Rejesus, R., Knoght, T. \& Scherrick, B. 2009. Factors Affecting Farmers' Utilization of Agricultural Risk Management Tools: The Case of Crop Insurance, Forward Contracting, and Spreading Sales. Journal of Agricultural and Applied Economics 41(1):107-123 